\title{
A Repression-derepression Mechanism Regulating the Transcription of Human Immunodeficiency Virus Type 1 In Primary $\mathrm{T}$ Cells
}

\author{
Athanasia Mouzaki' ${ }^{1}$ Arlette Doucet ${ }^{2}$, Emmanuel Mavroidis', \\ Lisbeth Muster ${ }^{3}$, and Duri Rungger ${ }^{3}$ \\ ${ }^{1}$ Experimental Hematology and Transfusion Medicine, Department of Medicine, \\ University of Patras, Patras, Greece \\ ${ }^{2}$ Division of Hematology, Department of Medicine, Geneva University Hospital, \\ Geneva, Switzerland \\ ${ }^{3}$ Station de Zoologie Expérimentale, University of Geneva, Chêne-Bougeries, \\ Switzerland
}

Accepted February 29, 2000.

\begin{abstract}
Background: Despite some controversy regarding the preferential infection and replication of human immunodeficiency virus type 1 (HIV-1), it appears that primary $\mathrm{T}$ lymphocytes, in their quiescent state, are nonpermissive for viral expression and propagation. Massive activation of viral gene expression occurs only when the host lymphocyte is activated. These observations prompted us to investigate the transcriptional regulation of HIV-1 in resting or activated $\mathrm{T}$ cells that were isolated from cord blood or adult peripheral blood.

Materials and Methods: To this end, we employed cellular purification and phenotyping techniques, in vitro protein-DNA binding studies, functional transactivation assays using proteins isolated from cord blood or adult peripheral blood $\mathrm{T}$ lymphocytes, and transfection experiments in primary $\mathrm{T}$ cells.
\end{abstract}

Results: We showed that transcription from the HIV-1 long terminal repeat is repressed in resting naive $\mathrm{T}$ lymphocytes; whereas, mitogenically stimulated $\mathrm{CD}^{+}$cells form an activator that derepresses transcription. Negative and positive regulation act through a repressor-activator target sequence (RATS), which shares homology with the interleukin-2 (IL-2) purine-rich response element, through the adjacent binding site of the nuclear factor of activated T cells (NFAT), and weakly, through the $\kappa \mathrm{B}$ region.

Conclusions: This regulation exerted by cellular transcription factors can account for several important features of HIV-1 expression in primary CD4 ${ }^{+}$ cells. Tight repression in resting naive $\mathrm{T}$ helper cells may be a main cause of viral latency and transcriptional activation accounts for massive viral production in activated $\mathrm{T}$ lymphocytes.

\section{Introduction}

Cells such as $\mathrm{T}$ lymphocytes and monocytederived macrophages, bearing the CD4 recep-

Address correspondence and reprint requests to: D. Rungger, Station de Zoologie Expérimentale, 154, route de Malagnou, $\mathrm{CH}-1224$ Chêne-Bougeries, Switzerland. Phone: ++41 22349 9925; Fax: ++41 22 349 2647; E-mail: rungger@sc2a.unige.ch tor and one or both of the co-receptors, CXCR4 or CCR5, are the main target of infection by human immunodeficiency virus type 1 (HIV-1) and disease progression is directly related to a gradual loss of $\mathrm{CD}^{+}$lymphocytes, accompanied by an increase in the viral burden $(1,2)$. Despite some controversy regarding the preferential infection and replication of HIV-1 (3), it 
appears that in their quiescent state, $\mathrm{T}$ lymphocytes are non-permissive for viral expression and propagation. Massive activation of viral gene expression occurs only when the host lymphocyte is activated (4-6). However, the cellular mechanism underlying latency and productive lytic activation is still poorly understood.

HIV-1 gene transcription is controlled by the interplay of viral and cellular transcription factors (TFs) interacting with sequence elements in the viral long terminal repeat (LTR), most of which interact with the core promoter and the upstream enhancer region (7-9). An ever increasing number of binding sites for cellular TFs has been identified (8-10). The activation of HIV-l transcription in response to mitogenic stimulation is triggered by the signaling pathways of the infected host cell (11). It was anticipated that this response is primarily controlled by cellular factors. Indeed, several sequence elements present in the LTR have been shown to be functionally involved in the response to T-cell activation, namely the $\kappa \mathrm{B}$ region $(6,12)$, with the cooperative interaction of Spl (13). The AP-1 site of the R/U5 region also participates in stimulation (14).

The so-called negative regulatory element (NRE), located between nucleotides -340 and -185 bp upstream of the transcriptor initiation site (15), contains a region (position -279 to -250) that shares extensive sequence homology with the interleukin-2 (IL-2) distal purinerich response elements and is alternatively called PRRE (16), IL-2 consensus sequence (17) or IL-2 homology region (6). Though it was occasionally also named (NFAT) motif (8), NFAT does not bind to this segment, but just downstream to it between positions -255 and -216 (18; Fig. 1). In the HIV-LTR, the PRRE and NFAT sites, thus, are not superimposed as in the IL-2 promoter, but sit side by side and exhibit astonishingly little sequence similarity.

The response of HIV-1 to host cell activation is strikingly similar to that of the IL-2 gene which, in the T leukemia Jurkat, is controlled by NFAT through the distal PRRE (19-22). For this reason, the HIV-1 PRRE, as well as the adjacent NFAT motif, are often considered as putative response elements to T-cell activation. In vivo footprinting patterns reveal changes in protein binding in the PRRE region and in the adjacent NFAT-binding site during T-cell activation (23). Attempts to functionally prove the involvement of PRRE and NFAT sites in HIV-1 activation gave contrasting results. In stably transfected T-cell lines, the HIV-1 LTR responds,
A HIV-1 LTR

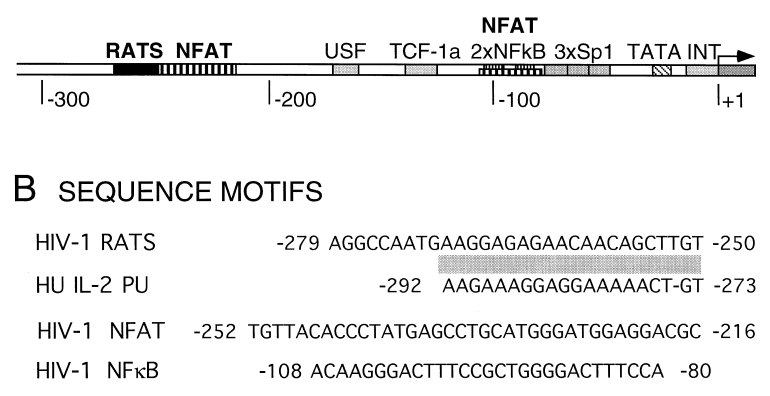

TARGET GENES
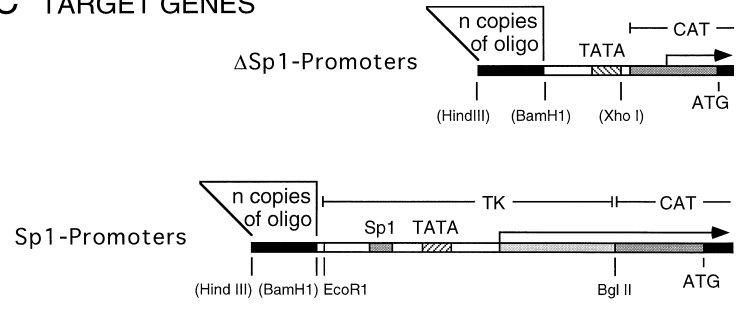

Fig. 1. HIV-1 LTR and derived target genes. (A) Relative position of relevant promoter elements within the human immunodeficiency virus type 1 (HIV-1) long terminal repeat (LTR). (B) Sequence and position of oligonucleotides used as probes in the bandshift assays, and as cis-acting elements inserted into the hybrid promoter of target genes. The interleukin-2 (IL-2) consensus sequence is marked by a grey bar. (C) Map of target genes containing one or several copies of single cis-acting elements. In the $\Delta \mathrm{Spl}$ promoters, the elements are linked by an irrelevant spacer to a TATA box followed by the gene coding for chloramphenicol-acetyl-transferase (CAT) and a polyadenylation signal. In the Spl promoters, an Spl site is intercalated between the cisactive element(s) and the TATA box. NFAT, nuclear factor of activated $T$ cells; $N F \kappa B$, nuclear factor kappa B.

similar to the IL-2 PRRE, to a variety of T-cell activation signals that trigger calcium increase and protein kinase C signals (24). Deletion of the PRRE element from the HIV-1 LTR results in increased transcription in the Jurkat $\mathrm{T}$ cell line (25) and the human melanoma cell line SK23 (16); whereas, a single PRRE in the context of a hybrid promoter mediates activation, indicative of a dual, negative and positive role of the PRRE (16). A (HeLa) cell protein was found to bind to the PRRE and to inhibit transcription in vitro (26). Most functional studies carried out with transfected Jurkat cells concluded, however, that the PRRE and/or NFAT motif play no, or only a minor, role in the activation of HIV-1 transcription in response to mitogenic stimulation of the host cell $(6,27,28)$. Surprisingly, NFAT also binds to a motif overlapping the $\kappa \mathrm{B}$ 
region, where it acts synergistically with nuclear factor (NF) $\kappa \mathrm{B}$ in the activation of HIV-1 transcription (29).

Over the past years, our laboratories reassessed the regulation of IL-2 transcription using in vitro protein-DNA binding studies, combined with functional transcription tests in the Xenopus oocyte system. Micro-injection of gene constructs with intact or mutant promoters or hybrid promoters containing individual control elements has been widely used in determining cis-active elements of a variety of genes, regardless of their species of origin $(30,31)$. Coinjection of putative regulatory proteins, or cDNA coding for such factors, also allows functional testing of transactive components of gene regulation (31-36).

Transactivation studies of the IL-2 promoter in this system were carried out with proteins prepared from ex vivo isolated T lymphocytes and revealed several novel aspects of IL-2 regulation. The IL-2 promoter is repressed by proteins from resting naive $\mathrm{CD} 4^{+}$cells. This repressor acts through the distal PRRE that is also the NFAT-binding site. Following T-cell activation, the repressor disappears and an activator is de novo synthesized. The activator also binds to the PRRE and switches on IL-2 transcription of previously repressed genes (derepression). In resting memory $\mathrm{T}$ cells, the activator is transferred to the cytoplasm, has a lower DNA affinity and is functionally incompetent. Upon stimulation of memory cells, this cytoplasmic form of activator is post-translationally modified within minutes, enters the nucleus again and activates IL-2 transcription (37-42). Though, in memory $\mathrm{T}$ cells the behavior of the activator is reminiscent of NFAT $(19,20)$, the two factors differ in many aspects. The most important difference is that proteins from activated Jurkat and (mouse thymoma) EL4 cell lines fail to derepress the previously silenced IL-2 promoter in functional assays $(41,42)$.

These findings prompted us to reinvestigate the regulation of HIV-l transcription by functional transactivation tests using proteins from primary $\mathrm{T}$ cells that were isolated from cord blood or peripheral blood (PB), instead of $\mathrm{T}$ cell line-derived NFAT. Constructs containing the entire HIV LTR controlling a cloramphenicol acetyl transferase (CAT) coding segment (pUC-BENN-CAT; 43) or various hybrid promoters containing the PRRE, NFAT, or $\mathrm{NF} \kappa \mathrm{B}$ motifs, were injected into the Xenopus oocyte, together with protein extracts from ex vivo-isolated $\mathrm{T}$ cells, or were transfected into primary resting T cells. The HIV- 1 LTR is regulated in a way similar to the IL-2 promoter. In the transactivation assays, proteins from resting naive $\mathrm{T}$ cells efficiently repressed basal transcription from the LTR; whereas, proteins from mitogen-stimulated cells derepressed transcription. The IL-2-like PRRE element functioned as a repressor-activator target sequence and we, thus, named it RATS. In addition, the NFAT binding site and, to a lesser extent, the $\mathrm{NF}_{\kappa} \mathrm{B}$ element also responded to the same stimuli. Regulation through RATS was also effective in ex-vivo isolated $T$ cells that, when transfected with the HIV-1 LTR or a 5xRATS-CAT construct, did not express detectable CAT activity, but transcription was induced following mitogenic stimulation of the host cells.

Repression of the HIV LTR by a cellular protein may account for the low transcription and replication of HIV- 1 in resting naive T lymphocytes and may be a main cause of viral latency and maintenance of viral reservoirs, despite long-term therapy. Derepression of the HIV-1 LTR represents a novel, possibly pivotal, additional trigger of the activation of HIV-1 transcription in activated $\mathrm{T}$ cells.

\section{Materials and Methods}

\section{Plasmids}

pUC-BENN-CAT (43) was a gift from the National Institutes of Health (NIH). It contained a full-length LTR from HIV-1, controlling a chloramphenicol acetyl transferase-coding sequence, followed by an SV40 polyadenylation signal. Target genes (Fig. 1) containing one copy of the individual cis-acting elements, RATS, NFAT, or $\mathrm{NF}_{\kappa} \mathrm{B}$ were produced as follows. In the $\triangle$ SPI series, the RATS, NFAT, or $\mathrm{NF} \kappa \mathrm{B}$ oligonucleotides (Fig. 1B) were linked to an oligonucleotide containing a spacer and a TATA box of a thymidine kinase (TK) gene. Such plasmids were produced by opening pBL-CAT3 (44) with HindIII and XhoI. Oligonucleotides corresponding to either one copy or a direct repeat with two copies of the different HIV-1 promoter elements (HindIIIBamHl compatible ends, phosphorylated) were inserted as single copies, together with a TATA-box oligo (BamHl-XhoI compatible ends, non-phosphorylated) by triple ligation. In the Spl series, the HIV-1 promoter elements preceded a truncated TK promoter containing the Spl site, TATA box and the first $52 \mathrm{nu}$ cleotides of the TK gene. These plasmids were 
constructed as follows. TK $\Delta 180$ (45) was cut with EcoR 1 that truncated the TK promoter at position -79 and cuts behind the TK gene. This fragment was inserted into pEMBL9 (46). From this intermediate, the HindIII/BglII promoter fragment was excised and inserted into the HindIII and BglII sites of pBL-CAT3, resulting in TK $\Delta 79$-CAT. This acceptor clone was opened by cutting with HindIII and BamHl and single copies or a direct repeat with two copies of the respective promoter elements were inserted using non-phosphorylated oligonucleotides. The 5xRATS-SpICAT clone was prepared differently. Oligonucleotides were synthesized with AA and TT ends, allowing for polymerization of multiple direct repeats. A pentamer was blunted by Klenow reaction and inserted into the SmaI site of TK $\Delta 79$-CAT. All clones were identified by extensive restriction analysis and some of them by additional Southern analysis. The human IL-2-CAT construct was from Paliogianni et al. (47). As controls, pSV2-CAT (48) was used in the injection experiments and CMVCAT (49) for transfections in T cells.

\section{Transfection of Resting PB T Cells and Control Cell Lines}

Heparinized venous blood was collected from healthy adult donors (Transfusion Center, Geneva University Hospital, Geneva, Switzerland). Mononuclear cells were prepared by centrifugation over a Ficoll-Paque gradient (Pharmacia, Dübendorf, Switzerland). T-cellenriched populations were obtained by rosetting with sheep erythrocytes as described (50). The cells were cultured in Optimem 1 culture medium (CM; GIBCO BRL, Basel, Switzerland) containing $10 \%$ fetal calf serum (FCS; GIBCO BRL, Gaithersburg, MD) and other supplements as described (51). Cells were cultured in the presence or absence of $10 \mathrm{ng} / \mathrm{ml}$ phorbol myristate acetate (PMA; Sigma, Buchs, Switzerland) and $5 \mu \mathrm{g} / \mathrm{ml}$ phytohaemaglutinine (PHA; Sigma) for $\mathrm{T}$ cells. $10^{7}$ cells per group were used per transfection. To transfect the cells, $15 \mu \mathrm{l}$ (DEAE) dextran (100 $\mu \mathrm{g} / \mathrm{ml}$, Sigma) were mixed with $30 \mu \mathrm{g}$ DNA (in $40 \mu \mathrm{l}$ TE buffer) and the DNA-mix was added to the cells which were suspended in $430 \mu \mathrm{l} \mathrm{CM}$ without FCS. DNA and cells were mixed and left to stand for $50 \mathrm{~min}$ at room temperature (RT). Then $3 \mathrm{ml}$ of 50 units $/ \mathrm{ml}$ heparin (Liquemine $^{\circledR}$, F. Hoffmann-La Roche, Basel, Switzerland) in CM without FCS were added to the cell-DNA mix, stirred briefly and immediately centrifuged at $1,500 \mathrm{rpm}$ for $5 \mathrm{~min}$. The cells were washed once in fresh CM without FCS, plated in $4 \mathrm{ml}$ complete CM, and incubated at $37^{\circ} \mathrm{C}$ with $5 \% \mathrm{CO}_{2}$ for 2 days. The $\mathrm{T}$ leukemia Jurkat and the promonocytic cell line U937 were transfected as described (52). For each CAT assay (see below), $5 \times 10^{6}$ cells were broken by sonication.

\section{Protein Extraction from T Cells, FACS Analysis and Bandshift Experiments}

$\mathrm{T}$ cells were isolated by the above procedure (cell transfection) from either PB or from blood of the umbilical cord. Non-stimulated PB T cells (T0) and non-stimulated cord blood T cells (C0) were used to produce repressor extracts. For activator extracts, the cells were stimulated with PHA and PMA (for conditions see cell transfection procedure above) for 4 (T4) or 10 hours (C10). In some experiments, the cells were purified further using anti-CD4-coated immunomagnetic beads (Dynal ${ }^{\circledR}$, Milan Analytica, La Roche, Switzerland). When required, the immunosuppressive drugs cyclosporin A (kind gift from Novartis, Basel, Switzerland) or FK506 (kind gift from Pfizer, Groton, CT) were added to the cultures at concentrations of $3 \mu \mathrm{g} / \mathrm{ml}$ and $20 \mathrm{ng} / \mathrm{ml}$, respectively. Aliquots of the cells used for preparing protein extracts were analyzed by fluorescence-activated cell sorter (FACS) to verify the frequency of naive $\left(\mathrm{CD} 4^{+} / \mathrm{CD} 45 \mathrm{RO}^{-}\right)$and memory $\left(\mathrm{CD}^{+} / \mathrm{CD} 4 \mathrm{RO}^{+}\right)$cells. The antibodies used for FACS analysis were from Daco A/S Denmark. The extracts were prepared from total cell lysates, following a procedure previously described (37). Cells were swollen in a hypotonic buffer, briefly sonicated, and salt was adjusted to $300 \mathrm{mM} \mathrm{KCl}$ to extract proteins from chromatin. After $20 \mathrm{~min}$ extraction on ice, the lysate was spun $\left(100,000 \mathrm{~g}\right.$ for $1 \mathrm{hr}$, at $\left.4^{\circ} \mathrm{C}\right)$, the supernatant dialyzed against injection buffer [containing $20 \mathrm{mM}$ N-2-hydroxyethylpiperazine-N-2-ethanesulfonic acid (HEPES) pH 7.6, $100 \mathrm{mM} \mathrm{KCl}, 0.02 \mathrm{mM}$ EDTA, $0.5 \mathrm{mM} \mathrm{1,4-}$ dithio-DL-threitol], and aliquots were rapidly frozen and stored at $-80^{\circ} \mathrm{C}$. Protein extracts from Jurkat cells were prepared as described (42). Protein concentration was measured by the Bradford assay. For bandshift assays, the protein extracts were precipitated by $10 \%$ weight by volume (w/v) polyethylene glycol (PEG8000), with constant stirring at $4^{\circ} \mathrm{C}$ for $20 \mathrm{~min}$. The proteins were then centrifuged at $10,000 \mathrm{~g}$ for 20 min and the pellet was redissolved in KIB buffer 
and stored. Bandshift assays (53) were carried out with probes corresponding to the HIV-1 RATS, NFAT, NF $\kappa$ B (Fig. 1B), an AP-1 probe or the IL-2 PRRE (41). The antibodies used for supershifts were from Santa Cruz Biotechnology Inc. (Dr. Glaser AG, Basel, Switzerland).

\section{Transactivation Assays In the Xenopus Oocyte}

The functional transcription test has been described earlier $(34,37,39)$. Briefly, putative repressors were microinjected into the oocyte cytoplasm from where they translocate to the nucleus. 2 hr later, the target genes were injected into the oocyte nucleus. Putative activators were added in a third, cytoplasmic injection shortly after the DNA. $10 \mathrm{nl}$ of DNA $(0.2 \mu \mathrm{g} / \mu \mathrm{l} ; 2 \mathrm{ng}$ total $)$ and $10 \mathrm{nl}$ extract ( $1 \mu \mathrm{g} / \mu \mathrm{l} ; 10 \mathrm{ng})$ of each protein extract were injected per oocyte. Batches of 15 oocytes were injected per one experimental point and after a $20 \mathrm{hr}$ incubation at $20^{\circ} \mathrm{C}, 10$ healthy oocytes were collected and processed for (CAT) assay.

\section{CAT Assays}

Small aliquots (usually $5 \mu \mathrm{l}$ of $200 \mu \mathrm{l}$ ) of the lysate obtained from 10 injected oocytes, or the entire lysate from $5 \times 10^{6}$ transfected cells, were processed for CAT assays (48). The thin layer chromatographs were exposed to autoradiography with Kodak BioMax film (Integra Biosciences Wallisellen, Switzerland). For quantification of acetylation, the films were scanned densitometrically (Molecular Dynamics, Sunnyvale, CA, or Ofoto 1.0.1., Onescanner) and the 1, 3, and $1 \& 3$ acetylated spots were divided by the total (acetylated plus unacetylated chloramphenicol). As verified on several occasions, the values closely corresponded to those obtained by cutting out the bands and counting radioactivity in a liquid scintillation counter.

\section{Results}

Putative Antigen Receptor Response Elements In the HIV-1 LTR

Among the numerous binding sites for cellular TFs that exist within the HIV-1 LTR, several sites share homology with the IL-2 promoter, in particular with signals that respond to mitogenic stimulation. A sequence element, named RATS here, is located between positions -279 and -250 of the LTR and shares extensive homology $(6,17)$ with the distal PRRE of the
IL-2 promoter that mediates the action of NFAT in Jurkat cells $(19,20)$. RATS responds to the repressor and activator proteins in primary $\mathrm{CD}^{+}$cells (41). In spite of the existing homology, this RATS segment of the HIV-1 LTR $(-269 /-250)$ does not bind NFAT. Indeed, NFAT- 1 footprints to a sequence stretch $(-255 /$ $-216)$ located just downstream (18) and to the $\kappa \mathrm{B}$ region located at position $-104 /-77$ (30). Fig. 1A sketches the HIV-1 LTR with the regulatory elements investigated here.

For the analysis of DNA-protein interactions in vitro, we used as probes the synthetic oligonucleotides specified in Fig. 1B. The same oligonucleotides were used to produce the various RATS, NFAT, or NF $\kappa$ B target genes for the functional transcription assays. In one series of target genes ( $\mathrm{Spl}$ promoters), the regulatory elements precede the Spl site and TATA box of the Herpes Simplex Virus thymidine kinase promoter. In the other series $(\Delta S p l-p r o m o t-$ ers), they are linked through a spacer segment without Spl motif to a synthetic TATA box (Fig. 1C).

\section{Regulation of the HIV-LTR Through RATS}

We initially compared the transcriptional activity of the HIV-1 LTR in $p U C-B E N N-C A T$ and the $2 X$ or $5 X$ RATS-CAT target genes with that of the $4 X P U-C A T$ gene, containing four copies of the IL-2 PRRE used in our previous studies on IL-2 gene regulation (37-42). Any gene injected at subsaturating concentrations into the oocyte nucleus displays consistent basal activity (34). So did the HIV-I LTR constructs. Basal transcription facilitated the observation of transcriptional repression. Protein extracts to be tested for repressor activity were injected first into the oocyte cytoplasm, from where nuclear proteins migrate to the nucleus. The target gene was injected into the nucleus $2 \mathrm{hr}$ later. If a repressor was present in the injected protein extract, basal activity was switched off. Inversely, the effects of transcriptional activators were best tested on previously silenced genes. Whereas, direct addition of activators to genes exhibiting basal activity resulted in only a weak stimulation over the basal level (maximum, 2-fold), derepression of silenced genes induced transcription to levels easily distinguishable from the repressed state. The outcome of such transcription assays with pUC-Benn-CAT and the $2 X$ and 5XRATS-CAT constructs are shown in Fig. 2A. The basal activity exhibited by the three target genes was re- 


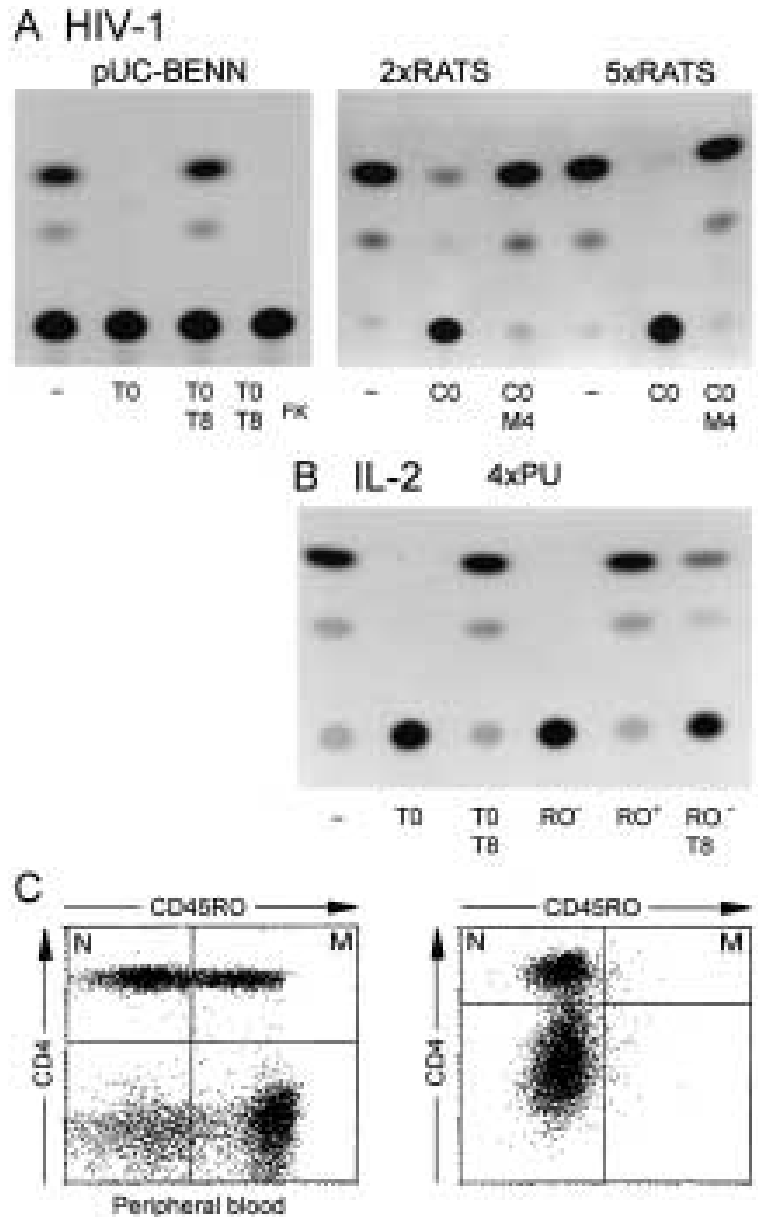

Fig. 2. The RATS element mediates repression and derepression of the human immunodeficiency virus type 1 (HIV-1) long terminal repeat (LTR). (A) Cloramphenicol acetyl transferase (CAT) assays of oocytes used in transactivation experiments. In a first injection, buffer (-) or protein extract from resting peripheral blood (PB) T cells (T0) or cord blood T cells (C0) were injected into the oocyte cytoplasm. $2 \mathrm{hr}$ later, the target genes $p U C-B E N N-C A T, 2 x R A T S-C A T$, or $5 \times R A T S-C A T$ were injected into the oocyte nucleus. When indicated, extract from PB T cells stimulated for $8 \mathrm{hr}$ in the absence (T8) or presence of the immunosuppressive drug FK506 $\left(\mathrm{T}^{\mathrm{FK}}\right)$ or from $4 \mathrm{hr}$-stimulated, purified memory T cells (M4) was added in a third, cytoplasmic injection. (B) Similar transactivation assay as in (A) using the $4 x P U-C A T$ gene containing the IL-2 PRRE and proteins from peripheral, resting (T0) or $8 \mathrm{hr}$-stimulated (T8) WBC or extracts from fluorescence-activated cell sorter (FACS)-purified $\mathrm{CD}^{+} / \mathrm{CD} 45 \mathrm{RO}^{-}$ $\left(\mathrm{RO}^{-}\right)$and $\mathrm{CD}^{+} / \mathrm{CD} 45 \mathrm{RO}^{+}\left(\mathrm{RO}^{+}\right)$cells. (C) FACS analysis of $\mathrm{PB}$ and cord blood T cells, using CD4 (green) and CD45RO (red) antibodies. N, naive; M, memory. pressed by the addition of proteins from unstimulated umbilical cord $T$ cells (mainly resting naive $\mathrm{T}$ cells) and from $\mathrm{PB}$ cells (resting naive and unstimulated memory $\mathrm{CD} 4^{+}$cells). Aliquots of the cells were analyzed by FACS for $\mathrm{CD} 4 \mathrm{CD} 45 \mathrm{RO}^{+}$(memory) to estimate the composition of the actual cell population used in naive $\left(\mathrm{CD} 4 \mathrm{CD} 45 \mathrm{RO}^{-}\right)$and memory $\mathrm{CD} 4$ cells (Fig. 2C). The subsequent injection of proteins from $8 \mathrm{hr}$-activated total $\mathrm{PB}$ cells, as well as from purified $\mathrm{T}$ helper memory cells stimulated for $4 \mathrm{hr}$, derepressed the HIV-1 LTR and the RATS promoter constructs. However, proteins from cells stimulated in the presence of the immunosuppressive drug FK506 failed to derepress transcription. A similar repression and derepression was obtained with the $4 X P U$ CAT clone, under the control of the distal IL-2 PRRE, using proteins from FACS-purified PBderived naive $\left(\mathrm{CD} 4^{+} \mathrm{CD} 45 \mathrm{RO}^{-}\right)$or memory $\left(\mathrm{CD}^{+} \mathrm{CD}^{-} 5 \mathrm{RO}^{+}\right.$) $\mathrm{T}$ helper cells (Fig. 2B). By these criteria, the HIV-1 RATS and IL-2 PRRE seemed functionally equivalent.

\section{Proteins from Resting and Stimulated T Cells Differentially Bandshift Several HIV Enhancer Elements}

In vitro interaction of proteins from resting and activated $\mathrm{T}$ cells with DNA probes corresponding to various HIV-1 LTR elements, was studied by bandshift assays. Protein extracts were prepared from resting and mitogen-stimulated $T$ cells from adult $P B$. Since bandshift assays with crude protein extracts rarely give satisfactory results, enriched protein fractions were prepared by polyethylene glycol precipitation.

Bandshifts with the activation protein (AP1) or the NF $\kappa$ B probe indicated successful mitogenic stimulation of the protein donor cells. As shown in Fig. 3A, the AP-1 probe was only faintly complexed by proteins from resting $T$ cells. By contrast, activated cells contained proteins that massively interacted with this probe. The formation of AP-1 complexes was a widely used criterion for successful mitogenic activation and AP- 1 also contributed to the activation of HIV transcription (14). The same held true for $\mathrm{NF} \kappa \mathrm{B}$, which is presently considered to be a key element in mitogenic $(6,12,25)$ and Tat-mediated activation (54-56). The $\kappa \mathrm{B}$ probe (Fig. 3A) more abundantly reacted with proteins from activated peripheral $\mathrm{T}$ cells. Some of the complexes were formed by $\mathrm{p} 50$ and $\mathrm{p} 65$ homo- and heterodimers, as indicated by the supershifts pro- 


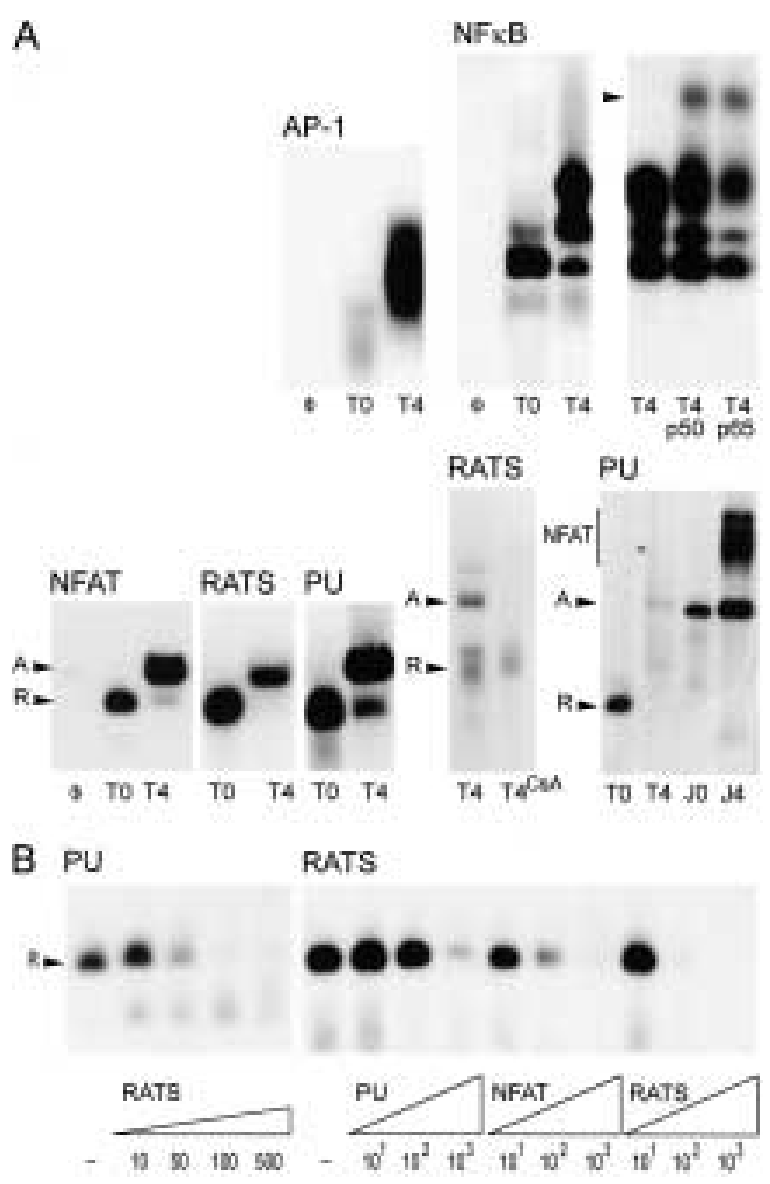

Fig. 3. Proteins from resting and stimulated $T$ cells differentially interact with several cis-acting elements. (A) Electrophoretic mobility shift assays were carried out with AP-1, $\mathrm{NF} \kappa \mathrm{B}, \mathrm{NFAT}$, or RATS probes corresponding to elements of the human immunodeficiency virus type 1 (HIV-1) long terminal repeat (LTR) and the PRRE (PU) of the interleukin-2 (IL-2) promoter. Proteins employed were from unstimulated (T0) and $4 \mathrm{hr}$-stimulated (T4) peripheral blood (PB) lymphocytes or from cells stimulated for $4 \mathrm{hr}$ in the presence of the immunosuppressive drug cyclosporin A $\left(\mathrm{T}^{\mathrm{CsA}}\right)$. In the upper right panel, antibodies directed against the NF $\kappa \mathrm{B}$ components p50 and p65, respectively, produced the supershift indicated by the arrowhead. The NFAT, RATS, and PU bandshifts form a fastmigrating complex with proteins from resting cells, corresponding to the repressor $(\mathrm{R})$, and a slow-migrating complex due to the activator (A). Proteins from unstimulated and $4 \mathrm{hr}$-activated Jurkat cells form complexes of different size (NFAT). $\Phi$, no protein added. (B) Competition experiments were carried out with labeled probe corresponding to the IL-2 PRRE (PU) or the HIV1 RATS element and extract displaying repressor activity from resting unstimulated PB lymphocytes (T0 in A). Cold oligonucleotides were added in the excess indicated on the bottom. duced by antibodies directed against these subunits of NF $\kappa$ B. Mitogenic stimulation of ex vivo $T$ cells, thus, produced the expected changes in $\mathrm{NF} \kappa \mathrm{B}$ reactivity. However, the $\kappa \mathrm{B}$ region also binds NFAT (29) and, as we show below, weakly responded to T-cell repressor and activator.

Proteins from unstimulated T cells that exhibit repressor activity in the transcription assay formed very similar, slow migrating complexes with the RATS probe, the IL-2 PRRE probe, and the HIV-1 NFAT motif (Fig. 3A). Upon mitogenic stimulation of $\mathrm{T}$ cells, the repressor complex disappeared and was replaced by a slower migrating band formed by activator protein. Proteins from cells stimulated in the presence of the immunosuppressive drug, cyclosporin A (CsA), did not form the activator complex. Similar bandshifts were also obtained with proteins from umbilical cord blood cells (not shown), except that, in these cells, the activator appeared only after 8 to $12 \mathrm{hr}$ of mitogenic stimulation (41). The correlation between the fast and slow migrating complexes, and repressor and activator activity, respectively, has been documented amply (37-41). Interestingly, the $\mathrm{T}$ cell activator formed a complex migrating much faster than the typical NFAT complexes obtained with proteins from stimulated Jurkat cells (Fig. 3A).

The comparable bandshift pattern observed with the HIV RATS and NFAT elements and the IL-2 PRRE probe suggest that similar proteins from $\mathrm{T}$ cells bind to these regulatory sites. This hypothesis was tested by competition experiments (Fig. 3B). The HIV RATS element efficiently competed for protein binding by the IL-2 PRRE. Inversely, the latter competed less efficiently with the RATS probe. The NFAT element competed with RATS nearly as well as the cold RATS probe itself. Random oligonucleotides or pBR322-HaeIII fragments did not compete (not shown). Competition for protein binding indicated that at least one subunit of the proteins binding to the IL-2 PRRE also was recognizing the RATS and NFAT motifs in the HIV-1 LTR.

In view of the observation that the NFAT element showed the same bandshift pattern as RATS, the functional role of the NFAT element had to be tested as well. Since the $\kappa \mathrm{B}$ region also harbors an NFAT-binding site (29), corresponding hybrid promoters were included in the following transactivation assays. 
The NFAT-binding Site and $\kappa B$ Region also Respond to T-Cell Signals

Transcription tests were carried out with target genes (Fig. 1C) under the control of the HIVLTR ( $p U C-B E N N-C A T)$, one, two, or five RATS elements, one NFAT site, or the $\kappa \mathrm{B}$ region (containing two $\mathrm{NF} \kappa \mathrm{B}$ binding sites and the overlapping NFAT binding region). These various cis-acting elements were either linked to an SPl site (Spl promoters) or directly to a TATA motif ( $\triangle$ SPl promoters). Transactivation was done with proteins from resting or stimulated PB T cells. Figure 4 shows a histogram representing the average transcriptional activity of each construct in at least three independent in-
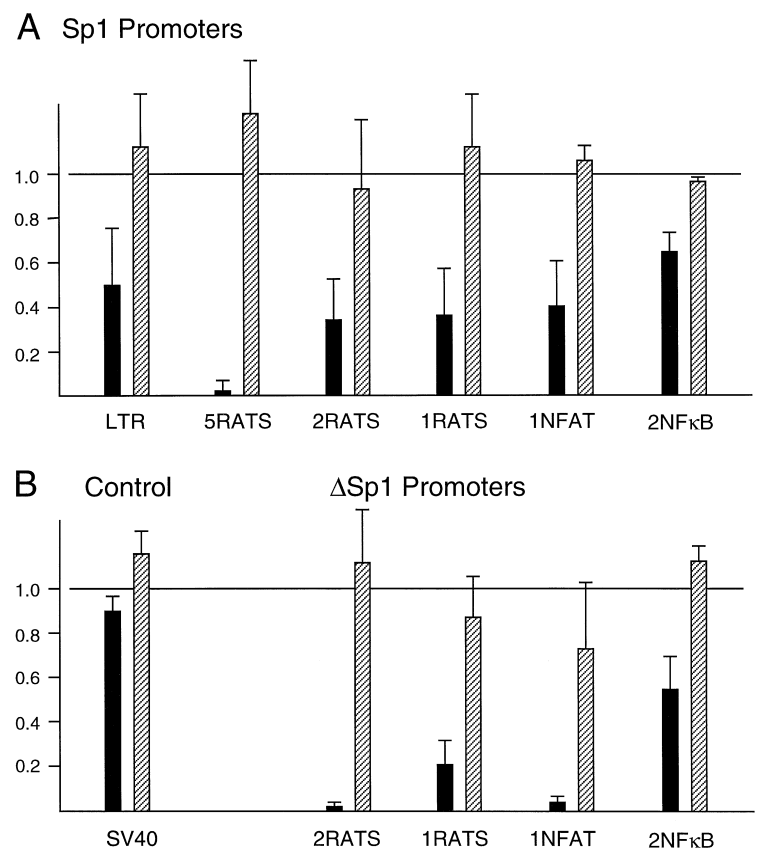

Fig. 4. Transcriptional regulation of the human immunodeficiency virus type 1 (HIV-1) long terminal repeat (LTR) is mediated by RATS, NFAT and NF $\kappa$ B elements. Histogram of mean cloramphenicol acetyl transferase (CAT) activity of 3 to 5 independent injection series. The basal activity displayed by each target gene in each series was set to 1 (horizontal line). CAT expression in the presence of protein was normalized to the basal level of each experimental group, averaged (columns) and the standard error mean determined (brackets). Extracts from resting peripheral $\mathrm{T}$ lymphocytes reduce target gene expression (black columns) and further addition of extracts from $4 \mathrm{hr}$-stimulated cells reestablishes CAT expression (hatched columns). (A) The target promoters contain an Spl site between the cis-acting element tested and the TATA box. (B) No Spl site is present in the $\Delta \mathrm{Spl}$ target promoters (see Fig. 1). $p S V 2-C A T$ under the control of an SV40 promoter served as a control. jection series. The repressed and derepressed activities were normalized to the basal activity (taken as 1) of the target gene in the same series and these values were averaged.

The data showed that transcription from the full-length HIV LTR was negatively regulated by proteins from resting cells and activity was re-established by the further addition of proteins from stimulated $\mathrm{T}$ cells. The RATS element exerted a similar regulation, whereby, an increased number of elements tightened the control. One copy of the NFAT binding site mediated the same response as one copy of RATS. The $\kappa \mathrm{B}$ region was repressed only weakly by proteins from resting $T$ cells, but this silencing was reproducible. This regulation acted in the presence of the Spl site (SPl promoter series, Fig. $4 \mathrm{~A})$ but is stricter in its absence $(\Delta \mathrm{Spl}$ promoter series, Fig. 4B). The Spl site, thus, seemed to act as a constitutive positive modulator. The response of the $\kappa \mathrm{B}$ element to T-cell signals in the absence of an Spl site indicated that the observed regulation may not be carried out by $\mathrm{NF} \kappa \mathrm{B}$, the activity of which depends on the presence of an Spl site (13). Instead, regulation may be carried out by proteins having an affinity to the coincident NFAT-binding motif (29). As a control, we used $p S V 2-C A T$. This gene was not markedly repressed by extracts from resting $\mathrm{T}$ cells.

The RATS Element Responds to Mitogenic Stimulation In Transfected T Cells

To verify the transcriptional regulation of the HIV LTR in T cells, we transfected the HIV-1 LTR-CAT clone, as well as a 5XRATSCAT target gene, into resting PB T cells. As a control for transfection success, we used a cytomegalo virus (CMV)-CAT plasmid and, as a T-cell-specific control, an IL-2-CAT plasmid. To be able to monitor transcription in resting $\mathrm{T}$ cells, transfection was carried out without prior mitogenic stimulation. For comparison, the T-cell line Jurkat and the monocytic cell line U937 were subjected to the same transfection protocols. Results are summarized in Table 1.

The constitutive CMV promoter directed sustained transcription in all cell types tested. The IL-2 CAT gene directed very low CAT activity in unstimulated Jurkat and none in resting PB $T$ cells. Its transcription was strongly activated in both stimulated Jurkat and primary $\mathrm{T}$ cells, but remained inactive in 
Table 1. Response of the transfected human HIV-1-CAT and control plasmids in ex vivo $\mathrm{T}$ cells and control cell lines

\begin{tabular}{|c|c|c|c|c|c|}
\hline DNA Clone & Cell Type & Stimulus & $\begin{array}{l}\text { CAT Activity } \\
\text { (\% acetylation) }\end{array}$ & Inducibility & No. of Expts. \\
\hline $\begin{array}{l}\text { CMV-CAT } \\
\text { (transfection } \\
\text { control) }\end{array}$ & $\begin{array}{l}\text { Jurkat } \\
\text { U937 } \\
\text { PB T cells }\end{array}$ & $\begin{array}{l}\text { CM } \\
\text { PHA/PMA } \\
\text { CM } \\
\text { PHA/PMA } \\
\text { CM } \\
\text { PHA/PMA }\end{array}$ & $\begin{aligned} 78.1 & ( \pm 9.6) \\
90.1 & (85.0 / 95.2) \\
30.7 & ( \pm 13.0) \\
56.2 & ( \pm 8.5) \\
6.2 & (5.5 / 7.0) \\
6.8 & (5.6 / 8.0)\end{aligned}$ & $\begin{array}{r}\times 1.15 \\
\times 1.83 \\
\times 1.10\end{array}$ & $\begin{array}{l}3 \\
2 \\
4 \\
3 \\
2 \\
2\end{array}$ \\
\hline $\begin{array}{l}\text { IL-2-CAT } \\
\text { (T-cell-specific } \\
\text { control) }\end{array}$ & $\begin{array}{l}\text { Jurkat } \\
\text { U937 } \\
\text { PB T cells }\end{array}$ & $\begin{array}{l}\text { CM } \\
\text { PHA/PMA } \\
\text { CM } \\
\text { PHA/PMA } \\
\text { CM } \\
\text { PHA/PMA }\end{array}$ & $\begin{array}{c}0.6( \pm 0.4) \\
43.0( \pm 5.9) \\
0.6(0.9 / 0.3) \\
0.6(0.8 / 0.4) \\
0.1(0.0-0.2) \\
3.9( \pm 1.1)\end{array}$ & $\begin{array}{l}\times 71.67 \\
\times 1.00 \\
\times 39.00\end{array}$ & $\begin{array}{l}3 \\
3 \\
2 \\
2 \\
3 \\
3\end{array}$ \\
\hline $\begin{array}{l}\text { pUC-BENN-CAT } \\
\text { (HIV-1 LTR) }\end{array}$ & $\begin{array}{l}\text { Jurkat } \\
\text { U937 } \\
\text { PB T cells }\end{array}$ & $\begin{array}{l}\text { CM } \\
\text { PHA/PMA } \\
\text { CM } \\
\text { PHA/PMA } \\
\text { CM } \\
\text { PHA/PMA }\end{array}$ & $\begin{aligned} 6.3 & ( \pm 3.7) \\
16.9 & ( \pm 6.7) \\
0.8 & ( \pm 0.4) \\
0.7 & ( \pm 0.5) \\
0.7 & ( \pm 0.2) \\
3.7 & ( \pm 0.9)\end{aligned}$ & $\begin{array}{r}\times 2.68 \\
\times 0.87 \\
\times 5.29\end{array}$ & $\begin{array}{l}4 \\
4 \\
3 \\
3 \\
4 \\
3\end{array}$ \\
\hline 5X RATS-CAT & $\begin{array}{l}\text { Jurkat } \\
\text { U937 } \\
\text { PB T cells }\end{array}$ & $\begin{array}{l}\text { CM } \\
\text { PHA/PMA } \\
\text { CM } \\
\text { PHA/PMA } \\
\text { CM } \\
\text { PHA/PMA }\end{array}$ & $\begin{array}{c}0^{*} \\
0^{*} \\
0^{*} \\
0^{*} \\
0.4( \pm 0.2) \\
5.1( \pm 1.8)\end{array}$ & $\begin{array}{l}- \\
- \\
\times 12.75\end{array}$ & $\begin{array}{l}3 \\
3 \\
3 \\
3 \\
7 \\
5\end{array}$ \\
\hline
\end{tabular}

PB, peripheral blood; CM, control medium; $0^{*}$, nondetectable CAT activity; ( \pm SEM); PHA/PMA, phytohaemoglutinine $(5 \mu \mathrm{g} / \mathrm{ml}) /$ phorbol myristate acetate $(10 \mathrm{ng} / \mathrm{ml})$.

U937 cells. The latter observation could be due to the fact that U937 cells were cultured in PHA/PMA, and PMA induced the cells to differentiate to a nondividing, macrophage-like phenotype (57). The HIV-1 LTR in $p U C-B E N N$ $C A T$ was already expressed in nonstimulated Jurkat cells and transcription increased less than 3-fold when the host cells were stimulated. By contrast, the HIV-1 LTR was inactive in resting PB $T$ cells and the rate of transcription was increased by over 8-fold following mitogenic stimulation. In our experiments, the RATS hybrid promoter was inactive and noninducible in Jurkat and U937 cells. A contrasting observation that the PRRE (RATS) sustained basal activity and responded to mitogenic stimulation in Jurkat cells (16) might be due to the slightly different DNA segment used or to differences in the Jurkat cell clones. In any case, RATS was highly responsive to mitogenic stimulation in $\mathrm{PB}$ $\mathrm{T}$ cells.

\section{Discussion}

We describe a cellular mechanism controlling transcription from the HIV-1 LTR that is very similar to the one acting on the distal PRRE element of the IL-2 promoter in ex vivo $T$ helper cells (for model see 41). In the HIV-1 LTR, both the T-cell repressor and activator interact with several sequence elements. A single copy of the purine-rich sequence $(-279 /-250)$ that shares extensive sequence homology with the IL-2 PRRE (17) is capable of mediating this response and has, been therefore named RATS (repressor-activator target sequence). Earlier findings already indicated that this PRRE element exerts a dual, negative and positive control in HIV-1 transcription $(16,25)$. The NFAT-binding site (-255/-216) independently assumes the same function and with comparable efficiency. The two elements, which overlap in the IL-2 promoter, thus, share similar function. Although, no obvious 
sequence homology exists, besides some purine-rich stretches and similarly spaced G residues.

In addition, the $\kappa \mathrm{B}$ region $(-110 /-79)$ reacts to the same stimuli, mediating a weak repression with proteins from resting $\mathrm{T}$ cells and derepression with proteins from stimulated cells in the transactivation assay. It is possible, that activation through the $\kappa \mathrm{B}$ region is induced by binding of NF $\kappa$ B/Rel TFs [NFAT belongs to the Rel family of TFs also (22)]. It could also be induced by the T-cell activator binding to the NFAT motif found in this region (29). Indeed, in our experiments, regulation though the $\kappa \mathrm{B}$ region is more pronounced in the absence, than in the presence, of a Spl site. This, in view of the dependence of $\mathrm{NF} \kappa \mathrm{B}$ on SP1 (13), argues against the participation of $\mathrm{NF} \kappa \mathrm{B}$ in this process. This does not necessarily mean that the NF $\kappa \mathrm{B}$ components do not contribute to HIV activation, as was amply documented in immortalized cells $(6,12,25,54,55)$. However, it should be noted, that NFкB contribution in primary $\mathrm{T}$ cells seems to be far less important than in cell lines (58) and it does not play a major role during primary $\mathrm{T}$ cell activation (59). The silencing observed here, also acting through the NFKB site, is most probably exerted by the same repressor that acts on the RATS and NFAT elements, but is less pronounced. This may be due to low binding affinity or the abundance of TFs interacting with this site, some of which are ubiquitous and are not subjected to changes during mitogenic activation.

Several arguments speak in favor of the idea that the same proteins act through the HIV-1 RATS and NFAT motifs, as well as through the IL-2 PRRE. Protein extracts from resting or activated $\mathrm{T}$ cells exert the same effect on these control elements. As shown here, the repressor complexes formed with these probes comigrate and the probes RATS and NFAT compete with each other for complex formation, indicating the existence of at least one common repressor subunit. Similarly, the same T-cell activator seems to bind to the IL-2 PRRE and the HIV-1 RATS and NFAT elements, as the bandshift complexes are indistinguishable. The precise relationship of the repressor and activator controlling the IL-2 promoter and HIV-1 LTR, respectively, may be determined once these proteins are purified and sequenced (work in progress).

By contrast, the T-cell activator seems to be different from Jurkat cell NFAT. The respective subunit composition, associated AP-1 factors and functional properties are not alike (41). Moreover, the complexes formed by activator from primary $\mathrm{T}$ cells and by NFAT from most Jurkat $\mathrm{T}$ cell lines are markedly different (Fig. 3). Most importantly, proteins from Jurkat and EL4 cells lines fail to derepress the IL2 promoter (42). As observed here, the T cell activator binds to the RATS and NFAT probes with similar affinity and both elements independently mediate the same transcriptional regulation. NFAT-1 protein, however, does not produce a footprint over the RATS region (18) and the RATS-CAT clone was not expressed in the Jurkat cell clone used in our transfection experiments. The binding motif for the two proteins must, therefore, be different, although they both bind to the PRRE region of the IL-2 promoter and contact at least two identical $G$ residues $(41,60)$. Such differences between IL-2 regulating factors and NFAT proteins are not surprising in view of recent findings on knockout mice, indicating that NFAT proteins are involved in the Th2 pathway and seem not to be involved in IL-2 regulation in primary $\mathrm{T}$ cells (61). Nonetheless, during mitogenic stimulation, both NFAT $(19,20)$ and the T-cell activator $(38,41)$ are modified through the same, calcineurin-dependent signaling pathway. The immunosuppressive drugs CsA and FK506 also prevent formation of functional activator acting on the HIV-1 LTR (Figures 2 and 3).

The important differences between primary T-cell activator and NFAT may explain why some attempts to demonstrate the functional role of NFAT in HIV-1 regulation, carried out with Jurkat cells, failed to prove this hypothesis $(6,27,28)$. Divergence of regulatory mechanisms in different cell types has been observed before. Contrary to the situation in Tcell lines, NF $\kappa \mathrm{B}$ is not capable of inducing HIV transcription in a $\mathrm{CD} 3^{+} \mathrm{CD} 4^{+} \mathrm{CD} 8^{-} \mathrm{T}$ cell clone (58). Moreover, the very low permissiveness offered by unstimulated CD4 T lymphocytes to HIV LTR functioning sharply contrasts with the high spontaneous LTR activity in cell lines (54). This is in agreement with our finding that the PRRE-specific repressor is exclusive to resting naive T helper cells $(39,41)$.

The fact that cellular factors are capable of regulating transcription through single elements of the HIV LTR in the oocyte transactivation system opens the question as to whether this mechanism is also functioning in the context of the intact LTR. This seems to be the case, 
as the full-length LTR in pUC-BENN-CAT does respond to repression and activation. Constitutive cis-acting activator elements may positively modulate the response of the intact LTR. For instance, the presence of a Spl site somewhat attenuates repression also in the oocyte system. The full-length LTR and the single control elements linked to a $\mathrm{Spl}$ site ( $\mathrm{Spl}$ promoters) are less tightly controlled than the target genes lacking an Spl site ( $\Delta$ Spl promoters).

In infected cells, viral transcription depends on integration of the viral DNA and the presence of the viral proteins Tat and Rev $(7,9,56)$. In the oocyte system, injected DNA remains episomal and is not integrated into the host genome, but is packed into nucleosomes (61). It is not known, however, whether the nucleosome spacing typical of the HIV LTR (10) is reproduced in these minichromosomes. As naked DNA is injected into the oocyte nucleus, it may bind endogenous general TFs before nucleosomes form (34), resulting in the sustained basal activity observed with most injected promoters and also with all the target genes tested in the present work. At present, we can only conclude that the observed repression and activation mechanism functions in the context of the intact LTR in nonintegrated, circular minichromosmes and in the absence of viral proteins. Moreover, the RATSCAT target gene transfected into resting $T$ helper cells is transcriptionally inactive, probably repressed, and becomes activated in response to host cell stimulation. We, therefore, think that the mechanism characterized in the Xenopus oocyte system also functions in $T$ helper cells in vivo.

The observed sensitivity of the activator to immunosuppressive drugs may, in part, explain the inhibitory effects of these compounds on viral production $(4,59,63)$. However, the drugs also interfere on different pathways, such as the calcineurin-dependent transactivation of the LTR by p53 (64). In addition, CsA inhibits cyclophilin A interactions with the Gag polyprotein, thus, inhibiting viral replication (65).

Conclusively, our observations show that both the PRRE motif, named RATS here, and the adjacent NFAT binding site (as defined by ref. 18) mediate HIV-l activation in response to mitogenic stimulation of $\mathrm{T}$ cells a longstanding postulate that could not be documented in established cell lines $(6,27,28)$. This regulation includes two levels, tight repression in resting naive $T$ cells and derepression following activation of the host cell. It will be interesting to clarify if, and how, this regulation is influenced by the function of RATS as a target of both viral Tat protein (66) and suppressive soluble factors from $\mathrm{CD}^{+}$cells (67). This repression-derepression mechanism, similar to the one controlling IL-2 transcription $(37,41)$, accomodates several important features of HIV1 expression. Tight transcriptional repression in resting naive $\mathrm{T}$ cells may be a main cause for viral latency. Resting naive $\mathrm{T}$ lymphocytes may, thus, constitute an important reservoir of virus that, in the absence of protein expression, may go undetected and escape treatment directed against viral functions. Upon first mitogenic activation of infected $T$ cells, a transcriptional activator formed by de novo synthesis (41), induces viral gene expression and replication. In resting memory cells, the activator is modified and resides in the cytoplasm in a nonfunctional state (41). Since no repressor is present in memory cells, viral transcription is not tightly repressed, but may eventually be activated to some extent through other positive control elements. Resting memory cells, thus, may constitute a less safe viral reservoir. Upon renewed stimulation of memory cells, the activator is modified through the calcineurin pathway within minutes (41) and activated memory cells become the site of massive viral production. This complex expression pattern of HIV-1 in $\mathrm{T}$ helper lymphocytes underscores the problems of antiviral treatment, the inaccessible viral reservoir residing in quiescent cells that need to be activated to replenish the depleted memory T-cell population and, in doing so, produce new virus.

\section{Acknowledgments}

We thank Dr. G. Pavlakis, Maryland, and Dr. R. Zufferey, Geneva, for critical comments on the manuscript, Dr. S. Thymianou, Patras, Mr. George Balanos, Patras, and Mr. M. Bacchetta, Geneva, for help with some of the experiments and Mr. S. Chraiti, Geneva, for the artwork. This work was supported by grants PENED/1274 from the Greek Ministry of Research and Technology and KARATHEODORIS/1952 from the University of Patras to A.M., by grant 31.46946.96 of the Swiss National Foundation, by the Sandoz Foundation, Basel, the Georges and Antoine Claraz Foundation, Zurich and the Societé Académique de Genève to D.R. 


\section{References}

1. Berger EA, Murphy PM, Farber JM. (1999) Chemokine receptors as HIV-1 coreceptors: roles in viral entry, tropism, and disease. Annu. Rev. Immunol. 17: 657-700.

2. Haase AT. (1999) Population biology of HIV-1 infection: Viral and $\mathrm{CD}^{+} \mathrm{T}$ cell demographics and dynamics in lymphatic tissues. Annu. Rev. Immunol. 17: 625-656.

3. Woods TC, Roberts BD, Butera ST, Folks TM. (1997) Loss of inducible virus in CD45RA naive cells after human immunodeficiency virus-1 entry accounts for preferential viral replication in CD45RO memory cells. Blood 89: 1635-1641.

4. Fauci AS. (1993) Multifactorial nature of human immunodeficiency virus disease: Implications for therapy. Science 262: 1011-1018.

5. Greene WC. (1990) Regulation of HIV-1 gene expression. Annu. Rev. Immunol. 8: 453-475.

6. Tong-Starksen SE, Luciw PA, Peterlin BM. (1987) Human immunodeficiency virus long terminal repeat responds to T-cell activation signals. Proc. Natl. Acad. Sci. U.S.A. 84: 6845-6849.

7. Cullen BR. (1991) Regulation of HIV-1 gene expression. FASEB J. 5: 2361-2368.

8. Gaynor R. (1992) Cellular transcription factors involved in the regulation of HIV-1 gene expression. AIDS 6: 347-363.

9. Hazeltine WA. (1991) Molecular Biology of the human immunodeficiency virus type 1. FASEB J. 5: 2349-2360.

10. Mirkovitch J. (1997) The role of chromatin in HIV-1 transcriptional regulation. Immunobiol. 198: 279-290.

11. Virelizier JL. (1989) Cellular activation and human immunodeficiency virus infection. Curr. Opin. Immunol. 2: 409-413.

12. Lodie TA, Reiner M, Coniglio S, Viglianti G, Fenton MJ. (1998) Both PU.1 and nuclear factorkappa B mediate lipopolysaccharide-induced HIV-1 long terminal repeat transcription in macrophages. J. Immunol. 161: 268-276.

13. Perkins ND, Edwards NL, Duckett CS, Agranoff AB, Schmid RM, Nabel GJ. (1993) A cooperative interaction between $\mathrm{NF} \kappa \mathrm{B}$ and $\mathrm{Spl}$ is required for HIV-1 enhancer activation. EMBO J. 12: 3551-1558.

14. Roebuck KA, Gu DS, Kagnoff MF. (1996) Activation protein-1 cooperates with phorbol ester activation signals to increase HIV-1 expression. AIDS 10: 819-826.

15. Rosen CA, Sodroski JG, Hazeltine WA. (1985) The location of cis-acting regulatory sequences in the human $\mathrm{T}$ cell lymphotropic virus type III (HLV-III/LAV) long terminal repeat. Cell 41: 813-823.

16. Sikder SK, Mitra D, Laurence J. (1994) Identification of a novel cell-type and context specific enhancer within the negative regulatory ele- ment of the human immunodeficiency virus type 1 long terminal repeat. Arch. Virol. 137: 139-147.

17. Fujita T, Shibuya H, Ohashi T, Yamanishi K, Taniguchi T. (1988) Regulation of human interleukin-2 gene: Functional DNA sequences in the $5^{\prime}$ flanking region for the gene expression in activated T lymphocytes. Cell 46: 401-407.

18. Shaw JP, Utz PJ, Durand DB, Toole JJ, Emmel EA, Crabtree GR. (1988) Identification of a putative regulator of early $\mathrm{T}$ cell activation genes. Science 241: 202-205.

19. Crabtree GR, Clipstone NA. (1994) Signal transmission between the plasma membrane and nucleus of T lymphocytes. Annu. Rev. Biochem. 63: 1045-1083.

20. Jain J, Loh C, Rao A. (1995) Transcriptional regulation of the IL-2 gene. Curr. Opin. Immunol. 7: 333-342.

21. Rao A. (1994) NF-ATp: A transcription factor required for the coordinate induction of several cytokine genes. Immunol. Today 15: 274-281.

22. Rao A, Luo C, Hogan PG. (1997) Transcription factors of the NFAT family: Regulation and function. Annu. Rev. Immunol. 15: 707-747.

23. Demarchi F, D'agaro P, Falaschi A, Giacca M. (1993) In vivo footprinting analysis of constitutive and inducible protein-DNA interactions at the long terminal repeat of human immunodeficiency virus type 1. J. Virol. 67: 7450-7460.

24. Copeland KF, Hendrix PJ, Haaksma AG, et al. (1995) Comparison of the response to T-cell activation by integrated HIV-1 and HTLV-1 LTRlacZ vectors. Virology 209: 633-636.

25. Lu YC, Touzjian N, Stenzel M, Dorfman T, Sodroski JG, Hazeltine WA. (1991) The NF kappa B independent cisacting sequences in HIV-1 LTR responsive to T-cell activation. J. Acquir. Immune Defic. Syndr. 4: 173-177.

26. West M, Mikovits J, Princkler G, et al. (1992) Characterization and purification of a novel transcriptional repressor from HeLa cell nuclear extracts recognizing the negative regulatory element region of human immunodeficiency virus-1 long terminal repeat. J. Biol. Chem. 267: 24948-24952.

27. Gruters RA, Otta SA, Al BJ, et al. (1991) Nonmitogenic $T$ cell activation signals are sufficient for induction of human immunodeficiency virus transcription. Eur. J. Immunol. 21: 167-172.

28. Markovitz DM, Hannibal MC, Smith MJ, Cossmann R, Nabel GJ. (1992) Activation of the human immunodeficiency virus type 1 enhancer is not dependent on NFAT-1. J. Virol. 66: 3961-3965.

29. Kinoshita S, Su L, Amano M, Timmermann LA, Kaneshima H, Nolan GP. (1997) The T cell activation factor NF-ATc positively regulates HIV-1 replication and gene expression in $\mathrm{T}$ cells. Immunity 6: 235-244.

30. Dawid IB, Sargent TD. (1988) Xenopus laevis in 
developmental and molecular biology. Science 240: 1443-1448.

31. Mous J, Stunnenberg H, Georgiev O, Birnstiel ML. (1985) Stimulation of sea urchin HB gene transcription by a chromatin associated protein fraction depends on gene sequences downstream of the transcription start site. Mol. Cell. Biol. 5: 2764-2769.

32. Wu C, Wilson S, Walker B, et al. (1987) Purification and properties of Drosophila heat shock activator proteins. Science 238: 1247-1253.

33. Maxson $R$, Ito $M$, Balcells $S$, et al. (1988) Differential stimulation of the sea urchin early and late histone gene expresssion by a gastrula nuclear extract after injection into Xenopus oocytes. Mol. Cell. Biol. 8: 1236-1246.

34. Rungger D, Muster L, Boeck R, Nichols A. (1990) Tissue-specific trans-activation of the rabbit $\beta$-globin promoter in Xenopus oocytes. Differentiation 44: 8-17.

35. Xu L, Rungger D, Georgiev O, Seipel K, Schaffner W. (1994) Different potential of cellular and viral activators of transcription revealed in oocytes and early embryos of Xenopus laevis. Biol. Chem. Hoppe-Seyler 375: 105-112.

36. Zuo J, Rungger D, Voellmy R. (1995) Multiple layers of regulation of human heat shock transcription factor 1. Mol. Cell. Biol. 15: 4319-4330.

37. Mouzaki A, Weil R, Muster L, Rungger D. (1991) Silencing and trans-activation of the mouse IL-2 gene in Xenopus oocytes by proteins from resting, mitogen-induced and cyclosporin A-treated primary T-lymphocytes. EMBO J. 10: 1389-1406.

38. Mouzaki A, Dai Y, Weil R, Rungger D. (1992) The immunosuppressive agents cyclosporin A and FK506 prevent normal derepression of the mouse IL-2 gene upon T-cellular induction. $C y$ tokine 4: 151-160.

39. Mouzaki A, Zubler RH, Doucet A, Rungger D. (1992) Trans-active factors controlling the IL-2 gene in adult human T-cell subsets. Mediators of Inflammation 1: 33-37.

40. Mouzaki A, Rungger D, Tucci A, Doucet A, Zubler RH. (1993) Occurrence of a silencer of the interleukin-2 gene in naive but not in memory resting $\mathrm{T}$ helper lymphocytes. Eur. J. Immunol. 23: 1469-1474.

41. Mouzaki A, Rungger D. (1994) Properties of transcription factors regulating interleukin 2 gene transcription through the NFAT binding site in untreated or drug-treated naive and memory T helper cells. Blood 84: 2612-2621.

42. Mouzaki A, Rungger D. (1994) Interleukin 2 gene regulation at the Pud (NFAT) promoter element: The complex situation in primary $\mathrm{T}$ lymphocytes. Molec. Biol. Haematopoiesis 3: 475-486.

43. Gendelman HE, Phelps W, Feigenbaum L, et al. (1986) Trans-activation of the human immunodeficiency virus long terminal repeat sequence by DNA viruses. Proc. Natl. Acad. Sci. U.S.A. 83: 9759-9763.

44. Luckow B, Schütz G. (1987) CAT constructions with multiple unique restriction sites for the functional analysis of eukaryotic promoters and regulatory elements. Nucleic Acids Res. 15: 5490.

45. Cochran MD, Weissmann C. (1984) Modular structure of the beta-globin and the TK promoter. EMBO J. 3: 2453-2459.

46. Dente L, Cesareni G, Cortese R. (1983) pEMBL: a new family of single stranded plasmids. Nucleic Acids Res. 11: 1645-1655.

47. Paliogianni F, Raptis A, Ahuja SS, Najjar SM, Boumpas DT. (1993) Negative transcriptional regulation of human interleukin 2 gene by glucocorticoids through interference with nuclear transcription factors AP-1 and NF-AT. J. Clin. Invest. 91: 1481-1489.

48. Gorman CM, Moffat LF, Howard BH. (1982) Recombinant genomes which express chloramphenicol acetyltransferase in mammalian cells. Mol. Cell. Biol. 2: 1044-1051.

49. Foecking MK, Hofstetter H. (1986) Powerful and versatile enhancer-promoter unit for mammalian expression vectors. Gene 45: 101-107.

50. Wen L, Hanvanich M, Werner-Favre C, Brouwers N, Perrin LH, Zubler RH. (1987) Limiting dilution assay for human $\mathrm{B}$ cells based on their activation by mutant EL4 thymoma cells: total and anti-malaria responder B cell frequencies. Eur. $J$. Immunol. 17: 887-896.

51. Novak TJ, Yoshimura FK, Rothenberg EV. (1992) In vitro transfection of fresh thymocytes and $\mathrm{T}$ cells shows subset-specific expression of viral promoters. Mol. Cell. Biol. 12: 1515-1527.

52. Mouzaki A, Serfling E, Zubler RH. (1995) Interleukin-2 promoter activity in Epstein-Barr virus-transfected B lymphocytes is controlled by nuclear factor $\kappa \mathrm{B}$. Eur. J. Immunol. 25: $2177-$ 2182.

53. Schreiber E, Matthias $P$, Müller MM, Schaffner W. (1988) Identification of a novel lymphoid specific octamer binding protein (OTF-2B) by proteolytic clipping bandshift assay (PCB). ЕМВО J. 7: 422 1-4229.

54. Alcami J, Lain de Lera T, Folgueira L, et al. (1995) Absolute dependence on kappa B response elements for initiation and Tat-mediated amplification of HIV transcription in blood CD4 T lymphocytes. EMBO J. 14: 1552-1560.

55. Harhaj E, Blaney J, Milhouse S, Sun S-C. (1996) Differential effects of $\mathrm{i} \kappa \mathrm{B}$ molecules on Tatmediated transactivation of HIV-1 LTR. Virology 216: 284-287.

56. Wright CM, Felber BK, Paskalis H, Pavlakis GN. (1986) Expression and characterization of the trans-activator of HTLV-III/LAV virus. Science 234: 988-992.

57. Bernstein MS, Tong-Starksen SE, Locksley RM. 
(1991) Activation of human monocyte-derived macrophages with Lipopolysaccharide decreases Human Immunodeficiency Virus replication in vitro at the level of gene expression. J. Clin. Invest. 88: $540-545$.

58. Hazan U, Thomas D, Alcami J, et al. (1990) Stimulation of a human T-cell clone with antiCD3 or tumor necrosis factor induces $\mathrm{NF} \kappa \mathrm{B}$ translocation but not human immunodeficiency virus 1 enhancer-dependent transcription. Proc. Natl. Acad. Sci. U.S.A. 87: 7861-7865.

59. Kinoshita S, Chen BK, Kaneshima H, Nolan GP. (1998) Host control of HIV-1 parasitism in T cells by the nuclear factor of activated T cells. Cell 95: 595-604.

60. Boise LH, Petryniak B, Mao X, et al. (1993) The NFAT- 1 DNA binding complex in activated $T$ cells contains Fra-1 and JunB. Mol. Cell. Biol. 13: 1911-1919.

61. Glimcher LH, Singh H. (1999) Transcription factors in lymphocyte development-T and B cells get together. Cell 96: 13-23.

62. Wyllie AH, Laskey RA, Finch J, Gurdon B. (1978) Selective DNA conservation and chromatin assembly after injection of SV40 DNA into Xenopus oocytes. Dev. Biol. 64: 178188.
63. Borvak J. (1996) The use of cyclosporine, FK506, and SDZ NIM811 to prevent CD25quiescent PB mononuclear cells from producing human immunodeficiency virus. J. Infect. Dis. 17: 850-853.

64. Gualberto A, Marquez G, Carballo M, et al. (1998) P53 transactivation of the HIV-1 long terminal repeat is blocked by PD 144795, a calcineurin-inhibitor with anti-HIV properties. J. Biol. Chem. 273: 7088-7093.

65. Franke EK, Luban J. (1996) Inhibition of HIV-1 replication by cyclosporine $\mathrm{A}$ or related compounds corelates with the ability to disrupt the Gag-cyclophilin A interaction. Virology 222: 279-282.

66. Vacca A, Farina M, Maroder M, et al. (1994) Human immunodeficiency virus type-1 Tat enhances interleukin-2 promoter activity through synergism with phobol ester and calciummediated activation of the NF-AT cis-regulatory motif. Biochem. Biophys. Res. Comm. 205: 467474.

67. Copeland KF, McKay PJ, Rosenthal KL. (1996) Suppression of the human immunodeficiency virus long terminal repeat by $\mathrm{CD}^{+} \mathrm{T}$ cells is dependent on the NFAT-1 element. AIDS Res. Hum. Retroviruses 12: 143-148. 